Check for updates

Cite this: RSC Adv., 2018, 8, 37008

Received 23rd August 2018

Accepted 23rd October 2018

DOI: $10.1039 / c 8 r a 07070 a$

rsc.li/rsc-advances

\section{Quantification of 71 detected elements from Li to U for aqueous samples by simultaneous-inductively coupled plasma-mass spectrometry $\dagger$}

\author{
Melanie Bäuchle, (D) ${ }^{a}$ Tina Lüdecke, (D) ${ }^{\text {ab }}$ Sasan Rabieh, (D) ${ }^{a}$ Khemet Calnek (D) ${ }^{a}$ \\ and Timothy G. Bromage iD *acd
}

Quantitative analysis of multi-element concentrations in aqueous solutions, such as water, beverages and biofluids, has long been performed by sequential inductively coupled plasma-mass spectrometry. Recently, a fully simultaneous mass spectrum monitoring ICP-MS instrument that fits a compact Mattauch-Herzog geometry (MH-ICP-MS) with a permanent magnet and a large, spatially resolving semiconductor ion detector has been introduced. This technology allows coverage of the complete inorganic relevant mass range from ${ }^{6} \mathrm{Li}$ to ${ }^{238} \mathrm{U}$ in a single measurement, which helps to mitigate the restriction on the number of inorganic elements whose concentrations may be routinely measured from one sample, thus reducing operational assay times and aqueous sample volumes for evaluations across the breadth of the periodic table. We report here on a detailed method for utilizing $\mathrm{MH}-\mathrm{ICP}-\mathrm{MS}$ to detect all elements of the relevant inorganic spectrum in aqueous samples; 7 types of water, 4 types of beverage, and 4 biofluid biological samples. With this method 71 elements can be routinely detected simultaneously in seconds and in as little as 1-4 mL sample, when using a specific set of calibration and internal standards. Quantitative results reveal distinct element patterns between each sample and within types of samples, suggesting that different types of aqueous solutions can be recognized and distinguished by their elemental patterns. The method has implications for understanding elemental distribution and concentration for many fields, including nutrition, studies of the biosphere, ecological stoichiometry, and environmental health fields, among others, where broad elemental information is actually required.

\section{Introduction}

Pure water is almost non-existent in nature. What generally is called water is actually an accumulation of dissolved elements in the form of organic (typically carbon-hydrogen-based) and inorganic (non-organic) molecules. Given the importance of water to all life, it came to our attention that aqueous samples are not routinely measured for all element concentrations across the breadth of the chemical periodic table, despite the potential for some technologies to do so. This dearth of research is not for the lack of want for knowledge, but because technologies and methods were not specifically designed to accommodate such breadth on a routine basis. Hence, in this

${ }^{a}$ Department of Biomaterials, New York University College of Dentistry, 345 East 24th Street, New York, NY 10010, USA. E-mail: tim.bromage@nyu.edu

${ }^{b}$ Senckenberg Biodiversity and Climate Research Center, Senckenberganlage 25, 60325 Frankfurt, Germany

'Department of Paleoanthropology, Senckenberg Research Institute, National History Museum, Senckenberganlage 25, 60325 Frankfurt, Germany

${ }^{d}$ Department of Basic Science and Craniofacial Biology, New York University College of Dentistry, 345 East 24th Street, New York, NY 10010, USA

$\dagger$ Electronic supplementary information (ESI) available. See DOI: 10.1039/c8ra07070a communication we report on a detailed method for the instantaneous detection of 71 inorganic element concentrations from ${ }^{7} \mathrm{Li}$ to ${ }^{238} \mathrm{U}$ from aqueous samples using MH-ICP-MS technology designed to provide this multi-element capability.

There are several techniques and methods presently in use to detect and quantify inorganic elements in fluids and water in particular, such as graphite furnace atomic absorption spectroscopy (GFAAS), inductively coupled plasma optical emission spectrometry (ICP-OES), and most prominently, quadrupole, sector field, and time of flight inductively coupled plasma mass spectrometry (Q-ICP-MS, SF-ICP-MS， ICP-TOF-MS respectively).$^{\mathbf{1 1 4}}$ These technologies were designed for targeted analyses of single or moderate numbers of elements. In particular, forms of ICP-MS have been successfully used for nearly three decades to determine concentrations of some multiple number of elements, mostly trace elements or rare earth elements, in various water samples, ${ }^{3,6,8,15-17}$ wine, ${ }^{2,12,13}$ milk and formula, ${ }^{5,18,19}$ saliva, blood and urine, ${ }^{\mathbf{1 , 3 2 0 - 3 4}}$ liquefied tomatoes, ${ }^{35}$ as well as in sediments and rocks. ${ }^{6,36,37}$ Hence, ICP-MS technology is the technique issued by national and international guidelines to monitor, among others, inorganic water quality. ${ }^{6,16,38,39}$ However, ICP-MS studies rarely exceed measurement of 40 
elements due to the duty cycle and scanning characteristics of popular quadrupole-based mass analysers.

Until recently, most ICP-MS instruments have been so-called "sequential" ICP-MS, in which elements are analysed consecutively, one by one, including the 'almost simultaneous' ICPTOF-MS. ${ }^{40}$ However, the employ of ICP-MS requires that sample volumes be adjusted upward to accommodate measurements of increasingly comprehensive multi-element composition, increasing also the time and consumables required to operate such instruments. Thus while it is possible, it is somewhat impractical to evaluate the entire inorganic spectrum with ICPMS because this technology was not purposefully designed to perform such analyses.

MH-ICP-MS for simultaneous detection was developed to permit evaluation across the complete inorganic relevant spectrum from small sample volumes $(1-4 \mathrm{~mL})$ in seconds and potentially lower consumables costs. It uses a Mattauch-Herzog geometry in which the configuration of electrostatic and magnetic fields spreads the ions over the mass range and distributes them along a flat plane. ${ }^{41}$ This technology differs from multicollector-ICP-MS in that it incorporates a single detector with 4800 pixel elements, the dimension of which permits simultaneous detection of isotopes over the full relevant inorganic mass spectrum from ${ }^{6} \mathrm{Li}$ to ${ }^{238} \mathrm{U}$ (SPECTRO MS, SPECTRO Analytical Instruments $\mathrm{GmbH}$, Kleve, Germany); technical specifications can be found elsewhere. ${ }^{40}$ With this technology, targeted evaluations may be performed on any number of elements, while also permitting discovery-based research that would be impractical using sequential ICP-MS. However, the method has been lacking to quantitatively evaluate the complete spectrum using MH-ICP-MS, which we present here.

The need for such a method, especially for water, is justified by the lack of comprehensive data regarding element distributions and concentrations for most elements across the breadth of the inorganic spectrum..$^{24,42}$ For example, the European Union (EU) and the United States Environmental Protection Agency (EPA) are monitoring and have issued maximum concentration limits for a number of elements in drinking water considered to be health risks, ${ }^{43,44}$ yet many elements commonly known as harmful to human health, such as lithium or tin, are neither monitored nor regulated in drinking water. Hence, we don't know for the majority of elements which concentrations are normal, below, or above average.

The elemental content of water typically mirrors its natural environmental exposure; e.g. its mineral content reflects the geochemical environment through which water runs., ${ }^{3,42}$ Aqueous solutions employ water as a medium, and as such, in the case of, say, beverages, the elemental content will additionally include the effects of manufacturing processes. Aqueous biofluids primarily reflect biological functions and consumption and environmental exposure. Some aqueous solutions such as commercial milk, will include elemental signatures that reflect beverage manufacturing as well as those of biofluids. In all, aqueous solutions are expected to "fingerprint" their origin. Here we present an MH-ICP-MS calibration method to quantify the total elemental composition of aqueous samples by simultaneously measuring 71 elements from ${ }^{7} \mathrm{Li}$ to ${ }^{238} \mathrm{U}$ in a variety of water, beverage, and biofluid samples with the advantage of full spectrum monitoring in which no elemental information is lost and that is essential in several research areas.

\section{Experimental}

\section{Instrumentation}

All measurements were performed with a MH-ICP-MS SPECTRO MS (SPECTRO Analytical Instruments GmbH, Kleve, Germany). The SPECTRO MS was launched in 2010, and it fits a compact Mattauch-Herzog geometry with a permanent magnet and a large, spatially resolving semiconductor ion detector covering the complete inorganic relevant mass range from ${ }^{6} \mathrm{Li}$ to ${ }^{238} \mathrm{U}$ in a single measurement. Fluid samples were introduced via a Teledyne ASX-560 autosampler (Teledyne CETAC Technologies, Omaha, NE, USA) by pneumatic nebulization with ultrahigh purity argon as carrier gas (Airgas, Randor, PA, USA), using a SeaSpray nebulizer (Glass Expansion, Pocasset, MA, USA) and nickel sampler and skimmer cones (ICPMS Cones Limited, Tarvin Nr. Chester, Cheshire, United Kingdom). Typical operating parameters are given in ESI Table S1. $\dagger$

\section{Optimization and calibration}

Prior to making measurements, the SPECTRO MS is optimized by a routine to provide maximum sensitivity over the entire mass/ratio range with reasonably low levels of oxide ion formation $\left(\mathrm{BaO}^{+} / \mathrm{Ba}^{+}\right)$and for peak shape. ${ }^{30} \mathrm{Ba}^{++}$ranges from -0.007 to 0.081 counts per second (cps), and $\mathrm{BaO}$ from 0.003 to $0.592 \mathrm{cps}$, and background standard deviation (SD) values from 27 to $86 \mathrm{cps}$ (119 $\mathrm{cps}$ in alcoholic samples and $3673 \mathrm{cps}$ in biofluids), depending of the samples analysed. The optimization routine includes a detector calibration (DC) and an ICALisation for adjusting, if necessary, peak positions according to set references. It is carried out using SPECTRO MS software, Mass Analyzer Vision (v. 1.32.1405) and employ of the MERCK VI multi-element standard (Merck Multi element standard VI, Merck Darmstadt, Germany) solution at the concentration of 20 ppb. When alcoholic beverages were to be analysed, we added $0.9 \%(\mathrm{v} / \mathrm{v})$ dehydrated to match the physicochemical properties of the alcoholic samples.

\section{Consumables}

Reagents. Throughout the entire study, all standards, samples and other solutions (wash, rinse etc.) were prepared with de-ionized ultrapure water $(18.2 \mathrm{M} \Omega \mathrm{cm}$ ) (ELGA, Purelab®Ultrapure Water Purification Systems, Lane End, Buckinghamshire, UK) and acidified to $2 \%(\mathrm{v} / \mathrm{v})^{16,42}$ with ultrapure $65 \% \mathrm{HNO}_{3}$ (analytical-reagent grade, Merck, Darmstadt, Germany) to facilitate element release from sample tube surfaces. When needed, dehydrated ethanol $\left(\mathrm{C}_{2} \mathrm{H}_{5} \mathrm{OH}\right.$ with less than $0.1 \%(\mathrm{v} / \mathrm{v})$ water, DNAse and RNAse non-detected, Spectrum Chemical, Gardena, CA, USA) was added.

Containers and pipettes. All containers used were made of high density polyethylene (HDPE) ${ }^{20,42}$ and certified to be DNase/ 
RNase and pyrogen free. Containers used, either for holding samples, standards, reference materials, or blanks, were acid washed with $\mathrm{HNO}_{3}$ (ref. 2, 20, 24, 45 and 46) (for more information see ESI Text $\mathrm{S} 1 \dagger$ ). Pipette tips should be made of highly purified HDPE and meet EN ISO 86655 requirements.

\section{Standards preparation and procedures}

We achieve high pipetting precision and repeatability at room temperature from pipetting volumes of $10 \mu \mathrm{L}$ to $10 \mathrm{~mL}$ using the pipetting robot ANDREW (Andrew Alliance S.A., Geneva, Switzerland).

\section{Internal standards}

To account for day-to-day variability in instrument conditions (instrument drift and physical interferences) during the time of measurement, ${ }^{15}$ we chose isotopes as internal standards that are in close proximity (in terms of their atomic mass number) to the measured and calibrated elements, but that also cover the mass range $\left({ }^{7} \mathrm{Li}\right.$, to $\left.{ }^{238} \mathrm{U}\right)$ in a most uniform way.

To represent the entire mass spectrum, we found it best to

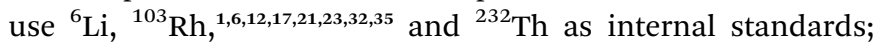
thus ${ }^{6} \mathrm{Li},{ }^{103} \mathrm{Rh}$, and ${ }^{232} \mathrm{Th}$ cannot be measured in test samples. We used internal standard stock solution concentrations of ${ }^{6} \mathrm{Li}$ (10 ppm), ${ }^{103} \mathrm{Rh}$ (2 ppm), and ${ }^{232} \mathrm{Th}$ (2 ppm) (LiRhTh) in order to overwhelm any traces of these elements/isotopes that might conceivably be found in a sample. The internal stock solution is made of single element standards of $\mathrm{Li}, \mathrm{Rh}$, and $\mathrm{Th}$ (Inorganic Ventures, Christiansburg, Virginia, USA). ${ }^{6} \mathrm{Li}$ was used for elements in the $m / z$ range of $7(\mathrm{Li})$ to $54(\mathrm{Fe}),{ }^{103} \mathrm{Rh}$ for the $\mathrm{m} / \mathrm{z}$ range $55(\mathrm{Mn})$ to $159(\mathrm{~Tb})$, and ${ }^{232} \mathrm{Th}$ for elements within $\mathrm{m} / \mathrm{z}$ range of 161 (Dy) to $238(\mathrm{U})$. We also achieved good results using ${ }^{89} \mathrm{Y}$ instead of ${ }^{103} \mathrm{Rh}$, and/or ${ }^{159} \mathrm{~Tb}$ instead of ${ }^{232} \mathrm{Th}$.

\section{Blank standard}

The blank standard is made of ultrapure water, $2 \%(\mathrm{v} / \mathrm{v})$ ultrapure $\mathrm{HNO}_{3}$ to facilitate element release from sample tube surfaces, ${ }^{40}$ and the internal standards LiRhTh.

\section{Calibration standards}

Up to 12 calibration standards (ESI Table S2 $\dagger$ ) were designed to calibrate all relevant elements between ${ }^{7} \mathrm{Li}$ and ${ }^{238} \mathrm{U}(\mathrm{Li}, \mathrm{Be}, \mathrm{B}, \mathrm{Na}$, $\mathrm{Mg}$, Al, Si, P, S, Cl, K, Ca, Sc, Ti, V, Cr, Mn, Fe, Co, Ni, Cu, Zn, Ga, $\mathrm{Ge}, \mathrm{As}, \mathrm{Se}, \mathrm{Br}, \mathrm{Rb}, \mathrm{Sr}, \mathrm{Y}, \mathrm{Zr}, \mathrm{Nb}, \mathrm{Mo}, \mathrm{Ru}, \mathrm{Pd}, \mathrm{Ag}, \mathrm{Cd}, \mathrm{In}, \mathrm{Sn}, \mathrm{Sb}, \mathrm{Te}$, I, Cs, Ba, La, Ce, Pr, Nd, Sm, Eu, Gd, Tb, Dy, Ho, Er, Tm, Yb, Lu, Hf, Ta, W, Re, Os, Ir, Pt, Au, Hg, Tl, Pb, Bi, and U). Each calibration standard contains ultrapure water, $2 \%$ ultrapure $\mathrm{HNO}_{3}$, and the internal standards LiRhTh, and 0.9\% (v/v) dehydrated ethanol for alcoholic beverages. In the case of Mix2 and Os calibration standards (see below), 0.5\% ultrapure $\mathrm{HCl}$ (Merck, Darmstadt, Germany) is added to ensure element stability. We grouped the 71 measurable elements into six standard groups: (1) the ICAL-Group (ICAL): ICAL is a 30 element multi standard in 5$10 \%(\mathrm{v} / \mathrm{v}) \mathrm{HNO}_{3}$ (Certipur® Certified Reference Material ICP multi-element standard VI: Merck KGaA, Germany) ${ }^{\mathbf{8 , 4 2}}$ and contains Li, Be, B, Na, Mg, Al, K, Ca, V, Cr, Mn, Fe, Co, Ni, Cu, Zn,
Ga, Ge, As, Se, Rb, Sr, Mo, Ag, Cd, Te, Ba, Tl, Pb, Bi and U in various concentrations. This ICAL multi standard is also used to calibrate the MH-ICP-MS each operational day; (2) the Mix1Group (Mix1): elemental composition is very similar to the ICAL-group, with the additional elements S, P, Si, In, Cs, but without Mo. These elements are mixed as Periodic Table Mix 1 for ICP (Trace cert ${ }^{\circledR}$ Sigma-Aldrich Production GmbH, Buchs, Switzerland) and are stored in $10 \%(\mathrm{w} / \mathrm{w}) \mathrm{HNO}_{3}$; (3) the Mix2-Group (Mix2): its elemental composition of Ti, Ge, $\mathrm{Zr}, \mathrm{Nb}, \mathrm{Mo}, \mathrm{Ru}, \mathrm{Rh}$, Pd, Sn, Sb, Hf, Ta, W, Re, Ir, Pt, and Au needs special storage conditions $\left(5 \%(\mathrm{w} / \mathrm{w}) \mathrm{HNO}_{3}\right.$ and $\left.1 \%(\mathrm{w} / \mathrm{w}) \mathrm{HF}\right)$ and are available through as Periodic Table Mix 2 for ICP (Trace cert ${ }^{\circledR}$ SigmaAldrich Production GmbH, Buchs, Switzerland); (4) the rare Earths- or Mix3-Group (Mix3): this group consists of elements belonging to the lanthanide series (La, Ce, Pr, Nd, Sm, Eu, Gd, Tb, Dy, Ho, Er, Tm, Yb, and Lu), as well as scandium (Sc) and yttrium (Y). They are contained in the Periodic Table Mix 3 for ICP (Trace cert ${ }^{\circ}$ Sigma-Aldrich Production GmbH, Buchs, Switzerland), in $5 \%(\mathrm{w} / \mathrm{w}) \mathrm{HNO}_{3}$; (5) the single element-group: these standards are all single elements and are either not present in any of the above groups $1-4$, or they are required in very different concentrations. Elements that belong to this group are: $\mathrm{Cl}$ and $\mathrm{Br}\left(\right.$ in $\mathrm{H}_{2} \mathrm{O}$ ), $\mathrm{K}$ (in $0.1 \% \mathrm{v} / \mathrm{v} \mathrm{HNO}_{3}$ ), In and $\mathrm{Ti}$ (in $2 \% \mathrm{v} / \mathrm{v} \mathrm{HNO}_{3}$ ), Cs (in 7\% v/v $\mathrm{HNO}_{3}$ ), $\mathrm{Hg}$ (in $10 \% \mathrm{v} / \mathrm{v} \mathrm{HNO}_{3}$ ), Os (in 10\% v/v HCl), and I (in 1\% TEA) (all acquired from: Inorganic Ventures, Christiansburg, Virginia, USAA). These elements are used as single element standards; (6) the multi-group (Multi): elements within this group are $\mathrm{P}$ and $\mathrm{S}$ (in $\mathrm{H}_{2} \mathrm{O}$ ), $\mathrm{Na}, \mathrm{Mg}, \mathrm{Ca}$, and $\mathrm{K}$ (in $0.1 \% \mathrm{v} / \mathrm{v} \mathrm{HNO}_{3}$ ), and $\mathrm{Si}$ (in tr. $\mathrm{HNO}_{3}$ and tr. HF) (all produced by Inorganic Ventures Christiansburg, Virginia, USA). The elements in this group are mixed into one solution in our laboratory, to account for the need of higher concentrations than found in the ICAL or Mix1 group. All elements, whether in mixes or as single element standards, are certified reference materials (CRM) that are directly traceable to the corresponding NIST SRM®. The six groups result in 11 (12 for biofluids) calibration standards, with at least two concentrations for each element, or a larger range of concentrations when needed. Concentrations of the calibration standards were chosen, with regard to the expected concentrations in test samples (see ESI Table S2 $\dagger$ ). Standards with elemental concentrations of less than $20 \mathrm{ppb}$ have to be prepared on the day of measurement to avoid degradation. Ideally, Mix2, Os and $\mathrm{Cl}$ calibrations standards should be prepared immediately prior to measurement.

\section{Reference material and controls}

To assure accuracy and reproducibility, we use the Standard Reference Material (SRM) NIST 1640a, as well as certified reference materials ICAL (20 ppb and $100 \mathrm{ppb}$ for wine), Mix 2 and Mix 3 (10 ppb), and the lower concentrated Multi standard. To furthermore account for the accuracy of measurements, ICAL 20 ppb was measured at least every 5 to 10 samples.

\section{Sample preparation and procedures}

We tested the method on 15 different types of aqueous sample, which include environmental water (tap, well, rain, lake, river, 
sea, and snow), beverages (bottled water, wine, beer and milk) and human biofluid samples (blood plasma, whole blood, saliva and urine) (Table 1). With the exception of the plasma and blood samples, all samples were collected directly into the prepared HDPE containers (Fischer Scientific, USA), without any intermediate container. The blood samples were collected into commercially available EDTA blood collection vials (BD Vacutainer ${ }^{\circledR} \mathrm{K}_{2}$ EDTA Tubes, Becton Dickinson, Franklin Lakes, NY, USA) and transferred into HDPE containers within $10 \mathrm{~min}$ of collection.
Upon arrival in the laboratory, all samples were acidified. Water samples were stored in a cool dark place, beverages and biofluids were refrigerated at $4{ }^{\circ} \mathrm{C}^{45}$ Further preparation and analysis were carried out at room temperature.

When dilution was required, samples were diluted with ultrapure water. For analysis, all (diluted) samples contain $2 \%$ (v/v) $\mathrm{HNO}_{3}$ and internal standards were added (1:100).

It has been reported that $\mathrm{Hg}$ is likely to be volatilized and adsorbed onto the inner walls of HDPE containers ${ }^{16}$ and that therefore chloride should be added to the sample to prevent the

Table 1 Aqueous samples

\begin{tabular}{|c|c|c|}
\hline Samples & Location & GPS Coordinates \\
\hline \multicolumn{3}{|l|}{ Environmental water } \\
\hline Tap water ( 0 and $5 \mathrm{~min})$ & Yonkers, NY, USA & Private home \\
\hline \multicolumn{3}{|l|}{ Well water } \\
\hline Well Karachi & Karachi, Pakistan & $24.8427554,67.061033299$ \\
\hline Well Mecca & Mecca, Saudi Arabia & $21.4226,39.8265000$ \\
\hline \multicolumn{3}{|l|}{ Snow } \\
\hline Sljeme Mountain & Zagreb, Croatia & $45.9142956,15.9745177$ \\
\hline Otzi the Iceman & Italy & $46.77891,10.839854$ \\
\hline \multicolumn{3}{|l|}{ Rain water } \\
\hline Porto Allegre & Porto Allegre, RS, Brazil & $-30.107778,-51.209444$ \\
\hline Karachi & Karachi, Pakistan & $24.8427554,67.06103329$ \\
\hline \multicolumn{3}{|l|}{ Lake water } \\
\hline Lake Zurich & Zürich, Switzerland & $47.358207,8.547451$ \\
\hline Lake TrećeJezero & Zagreb, Croatia & $45.824564,16.01882815$ \\
\hline \multicolumn{3}{|l|}{ River water } \\
\hline Medveščak feeder & Zagreb, Croatia & $45.890557,15.97427$ \\
\hline Oswegatchie river & Wegatchie, NY, USA & $44.304508,-75.587172$ \\
\hline \multicolumn{3}{|l|}{ Sea water } \\
\hline Fukuoka & Fukuoka, Japan & $33.596823,130.359027$ \\
\hline Copacabana Beach & Rio de Janeiro, RJ, Brazil & $-22.977854,-43.187257$ \\
\hline
\end{tabular}

\section{Beverage samples}

Bottled water

VOSS, Natural Artesian Water

Poland Spring, Natural Spring

Beer

Budweiser (glass, \#8071041B1310)

Heineken (can, \#8163528A0559)

Wine

'Old Soul' Petite Sirah, Oak Ridge Winery, Lodi 2015

Rio de Janeiro, RJ, Brazil

$-22.977854,-43.187257$

Familia Montana, Tempranillo

Reserva, Rioja DOCa 2012

Milk

Elmhurst Dairy (\#36-2107)

Farmland Fresh Dairies (\#42-169)

Vatnestrøm, Norway

Maine, USA

Anheuser-Busch, St. Louis, MO, USA

White Plains, NY, USA

Lodi, CA, USA

Fuenmayor, La Rioja, Spain

Worcester Crys DBA Mountainside Farm, Roxbury, NY, USA

Dairy, Pottsville Pike, Reading, PA, USA

New York City, NY, USA

New York City, NY, USA

New York City, NY, USA

New York City, NY, USA

New York City, NY, USA

New York City, NY, USA

New York City, NY, USA

New York City, NY, USA
$58.412781,8.084090$

N/A

N/A

N/A

38.136526, -121.2415530

$42.465949,-2.5599039999$

$42.306469,-74.549747$

$40.381500,-75.935056$

\section{Biofluid biological samples}

Male

Female

Female

Male

Blood plasma

Female

Male 
loss of $\mathrm{Hg} .{ }^{47}$ To avoid high percentages of total dissolved solids, in assessing the method for this communication we elected to test only the supernatants of milk, saliva, whole blood and plasma samples, without the employ of certified reference materials specifically associated with these sample types. Such samples as these generally should be acid digested in order to include the complete sample with its solids. Our future in depth MH-ICP-MS research on such categories of samples will be performed using acid digestion preparation protocols combined with the appropriate certified reference material standards.

Water samples. Except for sea water, water samples were not diluted. Tap water was collected as first water in the morning $(0$ min) and after 5 min of water discharge. The sea water samples were diluted $1: 20$ and $1: 40(\mathrm{v} / \mathrm{v})^{8}$ to enable quantification of elements in low and high concentrations.

Beverage samples. The wine samples were diluted $1: 10(\mathrm{v})$ $\mathrm{v})^{2,12,13}$ because of the high content of dissolved solids. The beer samples were shaken multiple times, then heated in a water bath for $20 \mathrm{~min}$ at $90{ }^{\circ} \mathrm{C}$ to eliminate carbon dioxide and subsequently diluted $1: 5$ and $1: 10(\mathrm{v} / \mathrm{v})$. The milk samples were diluted $1: 25(\mathrm{v} / \mathrm{v})$, as suggested by, ${ }^{31}$ because of the high content of dissolved solids. The diluted milk samples were vortexed for $2 \mathrm{~min}$ and then let stand to settle the solids. The supernatant was used for analysis. Milk and beer were collected from local supermarkets, and the wine was purchased in liquor retail stores in the U.S. Bottled water samples were not diluted.

Biofluid samples. All biofluid samples were collected in the morning on the same day, by one male and one female test person. All experiments were performed in compliance with the relevant laws and institutional guidelines of the U.S. Department of Health and Human Services Belmont Report, approved and performed by the Medical Director of the New York University College of Dentistry Health Screening Unit. Informed consent was obtained for any experimentation with human subjects.

In contrast to ref. 20, 27 and 31 who used a saliva collecting device, we collected the saliva directly into a prepared sample tube to avoid contamination from the saliva collecting device itself and its containing buffers.

The saliva was collected prior to eating, rinsing, and tooth brushing. In previous studies, saliva has been prepared by various procedures e.g. microwave ${ }^{48}$ or heat-acid ${ }^{22}$ digestion, using ultrasound, ${ }^{49,50}$ or without any digestion. ${ }^{20,27,32}$ Here, we acidified the saliva samples ( 1 to $2 \% \mathrm{HNO}_{3}$ (ref. 7, 32, 33 and 49-51)) and centrifuged ${ }^{33,49-51}$ them at $3500 \mathrm{rpm}$ for $40 \mathrm{~min}$. The supernatant was then diluted $1: 10(\mathrm{v} / \mathrm{v})$. The midstream urine samples were directly collected into $50 \mathrm{~mL}$ HDPE containers. The samples were acidified with $2 \%(\mathrm{v} / \mathrm{v}) \mathrm{HNO}_{3}$. For analysis, the urine samples were diluted $1: 2(\mathrm{v} / \mathrm{v})$ in contrast to published dilutions of $1: 5$ or $1: 10,{ }^{23,24}$ to ensure the recovery of low-concentration elements.

A fasting, venous blood sample was collected into two $\mathrm{K}_{2}$ EDTA blood collection vials via a pyrogen free blood collection set. The first collection vial was discharged to minimize contamination from the blood collection set. ${ }^{42}$ Blood from the second collection vial was used to generate two subsamples: whole blood and plasma. For the whole blood samples, $2 \mathrm{~mm}$ steel metal beads, washed overnight in ultrapure $2 \%(\mathrm{v} / \mathrm{v})$ $\mathrm{HNO}_{3}$, were added to the samples and the whole blood samples vortexed at about $2000 \mathrm{rpm}$ for $30 \mathrm{~s}$ in $4-6$ repeating cycles. The beads were removed and then the samples diluted $1: 100$. For the plasma samples, the blood was centrifuged for $20 \mathrm{~min}$ at $10500 \mathrm{rpm}$. The supernatant plasma was diluted $1: 10(\mathrm{v} / \mathrm{v})\left(\right.$ male) and $1: 20(\mathrm{v} / \mathrm{v})\left(\right.$ female) with $2 \%(\mathrm{v} / \mathrm{v}) \mathrm{HNO}_{3} \cdot{ }^{33}$

\section{Measurement procedure}

To achieve sound values for elements in each concentration for the blank, each calibration standard, controls and the samples, the respective solution is flushed into the MH-ICP-MS for at least $30 \mathrm{~s}$ after reaching the plasma, known as "preflush". Three aliquots are measured and a mean value for each measured isotope is established (isotopes monitored are given in ESI Table S3 $\dagger$ ). A total solution volume of $4 \mathrm{~mL}$ or greater is required at the minimum sample aspiration rate $\left(0.5 \mathrm{~mL} \mathrm{~min}^{-1}\right)$ when using an autosampler. When introducing samples, controls etc. manually, the volumes needed for analyses can be as low as 1 $\mathrm{mL}$.

Between the introduction of the blank, each calibration standard, controls and samples, the instrument is rinsed with an ultrapure $2 \%(\mathrm{v} / \mathrm{v}) \mathrm{HNO}_{3}$ for 2 min (ref. 15) (for water based samples) to $4 \mathrm{~min}$ (milk and blood samples), or longer if needed. The overall time per one sample analyses is about 5 min.

Generally, the MH-ICP-MS produces stable data over several hours and we measure up to 60 samples after the set of calibration standards, resulting in about $7 \mathrm{~h}$ per run. This time can vary based on preflush and rinse time or the number of aliquots analyzed.

\section{Analysis procedure}

Measured isotope peaks and backgrounds of the calibration standards and samples are manually defined.

In general, the SPECTRO MS software Mass Analyzer Vision (v. 1.32.1405) factors in the influence of interferers on a target isotope by adjusting the calibration regression of the target isotope providing a mathematically corrected elemental concentration. When an interfering element (e.g. its isotopes) is present in a different calibration standard than the target isotope, the SPECTRO MS software calculates the respective interferer-factor. We tested the interferences of elements (e.g. their isotopes) that influence isotopes of elements within the same calibration standards separately, for each matrix. These elements are the rare earth elements $\mathrm{Ce}$ to $\mathrm{Lu}$, as well as $\mathrm{Na}, \mathrm{Al}$, $\mathrm{Si}, \mathrm{S}, \mathrm{Ca}, \mathrm{Fe}, \mathrm{Mn}, \mathrm{Sr}, \mathrm{Nb}$ and I for non-alcoholic samples, and rare earth elements $\mathrm{La}$ to $\mathrm{Lu}$ and $\mathrm{Na}, \mathrm{Al}, \mathrm{Si}, \mathrm{S}, \mathrm{K}, \mathrm{Ca}, \mathrm{Cr}, \mathrm{Mn}, \mathrm{Fe}$, $\mathrm{Co}, \mathrm{Cu}, \mathrm{Sr}, \mathrm{Nb}, \mathrm{Mo}, \mathrm{Cd}$, and I for alcoholic samples. The respective interference factors were then used in measurements within one matrix group (e.g. all water sample, or samples containing alcohol). We also tested potential interferences in all sample types resulting from our internal standards $\mathrm{Li}, \mathrm{Rh}$, and Th, with negative results. A list of all interferer factors for all 
target isotopes in all measurement runs can be found in ESI Table S3. $\dagger$

To achieve a regression line with a correlation coefficient above, or equal to $R^{2}=0.996$ (higher than suggested by (ref. 23)), readings of the blank and at least two calibrations standards are plotted, and the influence of interferers factored in. Elements that did not achieve the set correlation coefficient in the samples tested here were ${ }^{27} \mathrm{Al}\left(R^{2}=0.975\right),{ }^{34} \mathrm{~S}\left(R^{2}=0.963\right.$, 0.976), ${ }^{42} \mathrm{Ca}\left(R^{2}=0.995\right)$, and ${ }^{127} \mathrm{I}\left(R^{2}=0.994,0.989\right)$ in the environmental waters, ${ }^{34} \mathrm{~S}\left(R^{2}=0.992\right),{ }^{35} \mathrm{Cl}\left(R^{2}=0.969\right)$, and ${ }^{49} \mathrm{Ti}\left(R^{2}=0.995\right)$ in bottled water, ${ }^{39} \mathrm{~K}\left(R^{2}=0.991\right),{ }^{49} \mathrm{Ti}\left(R^{2}=\right.$ $0.930),{ }^{62} \mathrm{Ni}\left(R^{2}=0.994\right),{ }^{90} \mathrm{Zr}\left(R^{2}=0.967\right),{ }^{178} \mathrm{Hf}\left(R^{2}=0.975\right)$ for alcoholic beverages, ${ }^{28} \mathrm{Si}\left(R^{2}=0.994\right),{ }^{34} \mathrm{~S}\left(R^{2}=0.992\right)$, and ${ }^{35} \mathrm{Cl}$ $\left(R^{2}=0.991\right)$ in milk, and ${ }^{28} \mathrm{Si}\left(R^{2}=0.995\right),{ }^{34} \mathrm{~S}\left(R^{2}=0.992\right)$, and ${ }^{35} \mathrm{Cl}\left(R^{2}=0.991\right)$ in body fluids. However, most isotopes had an $R^{2} \geq 0.999$ and some achieved a $R^{2}$ of 1 (environmental waters: ${ }^{11} \mathrm{~B},{ }^{23} \mathrm{Na},{ }^{24} \mathrm{Mg},{ }^{44} \mathrm{Ca},{ }^{90 / 91} \mathrm{Zr},{ }^{99 / 101} \mathrm{Ru},{ }^{108} \mathrm{Pd},{ }^{109} \mathrm{Ag},{ }^{111 / 112 / 114} \mathrm{Cd}$, ${ }^{118 / 120} \mathrm{Sn},{ }^{140} \mathrm{Ce},{ }^{143} \mathrm{Nd},{ }^{166 / 167} \mathrm{Er},{ }^{169} \mathrm{Tm},{ }^{172 / 173} \mathrm{Yb},{ }^{177 / 178 / 179} \mathrm{Hf}$, ${ }^{182} \mathrm{~W},{ }^{191} \mathrm{Ir},{ }^{197} \mathrm{Au},{ }^{207} \mathrm{~Pb}$, and ${ }^{209} \mathrm{Bi}$; bottled water: ${ }^{24} \mathrm{Mg},{ }^{39} \mathrm{~K}$, ${ }^{140} \mathrm{Ce},{ }^{162} \mathrm{Dy},{ }^{166 / 167} \mathrm{Er},{ }^{171 / 172} \mathrm{Yb},{ }^{182 / 184} \mathrm{~W}$, and ${ }^{187} \mathrm{Re}$; alcoholic beverages: ${ }^{9} \mathrm{Be},{ }^{45} \mathrm{Sc},{ }^{141} \mathrm{Pr},{ }^{157} \mathrm{Gd}$; milk: ${ }^{23} \mathrm{Na},{ }^{89} \mathrm{Y},{ }^{133} \mathrm{Cs},{ }^{139} \mathrm{La}$, ${ }^{141} \mathrm{Pr},{ }^{166} \mathrm{Er},{ }^{184} \mathrm{~W},{ }^{185} \mathrm{Re},{ }^{192} \mathrm{Os},{ }^{193} \mathrm{Ir}$; body fluids: ${ }^{23} \mathrm{Na},{ }^{24} \mathrm{Mg}$, ${ }^{39} \mathrm{~K},{ }^{89} \mathrm{Y},{ }^{133} \mathrm{Cs},{ }^{139} \mathrm{La},{ }^{141} \mathrm{Pr},{ }^{166} \mathrm{Er},{ }^{184} \mathrm{~W},{ }^{193} \mathrm{Ir}$, and $\left.{ }^{192} \mathrm{Os}\right)$.

When elemental concentration was measured on multiple isotopes (see ESI Table S3†), we selected the isotope with the lowest relative standard deviation using STOICHY software ${ }^{52}$ (OVAN GmbH, Berlin, Germany). Mean values of three consecutive measurements, relative standard deviation, and detection limits were recorded for each element.

\section{Results}

\section{1 elements simultaneously detected and quantified}

Mean elemental concentrations, relative standard deviations, and detection limits for each sample, as well as the control samples are reported in the ESI section. $\dagger$

\section{Environmental Water Samples}

Fig. 1A, ESI Tables S4.1-4.4. $\dagger$

Tap water (Yonkers, NY, USA, household). In water drawn immediately upon turning on the tap (Tap $0 \mathrm{~min}$ ), elements such as $\mathrm{Mg}, \mathrm{Si}, \mathrm{P}, \mathrm{Cr}, \mathrm{Fe}, \mathrm{Cu}, \mathrm{Zn}, \mathrm{Br}, \mathrm{Sr}$, and Re are more abundant. Elements such as $\mathrm{Al}, \mathrm{Mn}$, Co and $\mathrm{Ni}$ are at higher concentrations in water drawn after 5 min running (Tap $5 \mathrm{~min}$ ). The abundance of elements is higher in the $0 \mathrm{~min}$ tap water (37 elements), compared to water drawn after 5 min (34 elements).

Well water (1 and 2; Karachi, Pakistan and Mecca, SaudiArabia). Elemental abundance varies with respect to the number of elements found (Karachi: 39; Mecca 36) and the presence/absence of elements, e.g. more rare earth elements are present in the Karachi well then in the Mecca well. Most elements are more highly concentrated in the Karachi well (V, $\mathrm{Zn}, \mathrm{As}, \mathrm{Br}, \mathrm{Sr}, \mathrm{I}, \mathrm{Pb}$, and U).

Snow (Otzi the Iceman, Italy and Sljeme Mountain, Croatia). Both snow samples are very rich in elements (Otzi the Iceman: 50 elements, Sljeme Mountain: 42 elements). Overall, concentrations are considerably higher in snow from Italy. Both samples have a high abundance of transition metals and rare earth elements.

Rain (Porto Alegre, Brazil and Karachi, Pakistan). Rain from Porto Alegre clearly differs from Karachi rain in that there are fewer elements (Porto Alegre: 29, Karachi: 47) present and that elements found in both samples are significantly less concentrated (e.g. Al, Fe, Cu, Zn, Sr, Ba, and $\mathrm{Pb}$ ).

Lake water (Lake Zürich, Switzerland and Lake Treće Jezero, Croatia). More elements are abundant in Lake Treće Jazero (45), when compared to Lake Zurich (36), especially rare earth elements. Toxic elements, such as $\mathrm{As}, \mathrm{Cd}, \mathrm{Sb}, \mathrm{Hg}$ or $\mathrm{Pb}$ are more highly concentrated in the Croatian lake, or not present at all in the Swiss lake. Lake Treće Jezero is especially rich in $\mathrm{Al}$ and $\mathrm{Mn}$.

River water (Medveščak feeder, Croatia and Oswegatchie, USA). The Oswegatchie carries 11 more elements than the Medvešcak feeder (35 elements). Both rivers are rich in rare earth elements and in general, elemental concentrations are higher in the USA river, whereas $\mathrm{Ti}, \mathrm{Cd}, \mathrm{Sn}$ and $\mathrm{Hg}$ are only present in the Oswegatchie river. Here, the high amount of $\mathrm{Al}$ $\left(457 \mu \mathrm{g} \mathrm{L}^{-1}\right)$ is noteworthy.

Seawater (Fukuora, Japan and Copacabana, Brazil). Although we diluted the sea water samples $1: 40$, concentrations of $\mathrm{Na}, \mathrm{Mg}, \mathrm{S}$ and $\mathrm{Cl}$, still exceeded the set maximum calibration concentrations of $180 \mathrm{ppm}$ ( $\mathrm{Na}, \mathrm{Mg}$ ), $60 \mathrm{ppm}(\mathrm{S})$ and $360 \mathrm{ppm}(\mathrm{Cl})$. Therefore, data shown here refers to the $1: 20$ diluted sample. Seawater from Fukuora shows a high abundance of rare earth elements and higher concentrations of Co and $\mathrm{Pb}$. In total, the Fukuora sample contains 41 elements, in comparison to the Copacabana sample (30).

Elemental concentrations in environmental water were verified using ICAL, NIST 1640a CRM, Mix2, Mix3 and the mixture of single element reference materials $\mathrm{Na}, \mathrm{Mg}, \mathrm{Si}, \mathrm{P}, \mathrm{S}$, and $\mathrm{K}$ (Multi). Twenty-two were covered by multiple controls, and with the exception of $\mathrm{B}$ and $\mathrm{Fe}$, the controls were within the required $\pm 20 \%$ error margin. In samples of tap, well and rain waters, Lake Zurich and the Otzi snow sample, the low concentrations of iron may be slightly too high, as the lower concentrated control was measured at $125 \%$ of the reference concentration. Control concentrations of boron were at $67.6 \%$ only in one control and hence, the rivers, Trece Jezero and Sljeme samples might actually be higher, in contrast to iron, that has a control concentration of $168 \%$ above the anticipated concentration compared to NIST 1640a CRM (ESI Table S4.4†).

\section{Beverage samples}

Fig. 1B, ESI Tables S5.1 and 5.2. $\dagger$

Bottled water (VOSS and Poland Spring). Overall, VOSS contains more elements (40; Poland Spring: 32), especially rare earth elements. Transitional metals are more abundant in Poland Spring water. VOSS shows notably high concentrations in $\mathrm{Al}, \mathrm{Mn}, \mathrm{Fe}, \mathrm{Br}, \mathrm{Mo}, \mathrm{I}, \mathrm{Ba}, \mathrm{La}, \mathrm{Ce}$, and $\mathrm{Nd}$. The toxic elements lead $(\mathrm{Pb})$ and arsenic (As) are found in the Poland Spring water only.

Beer (Budweiser and Heineken). The Budweiser beer (43 elements) shows higher concentrations in $\mathrm{Mg}, \mathrm{Sc}, \mathrm{Fe}, \mathrm{Rb}, \mathrm{Sr}, \mathrm{Y}$, 
A

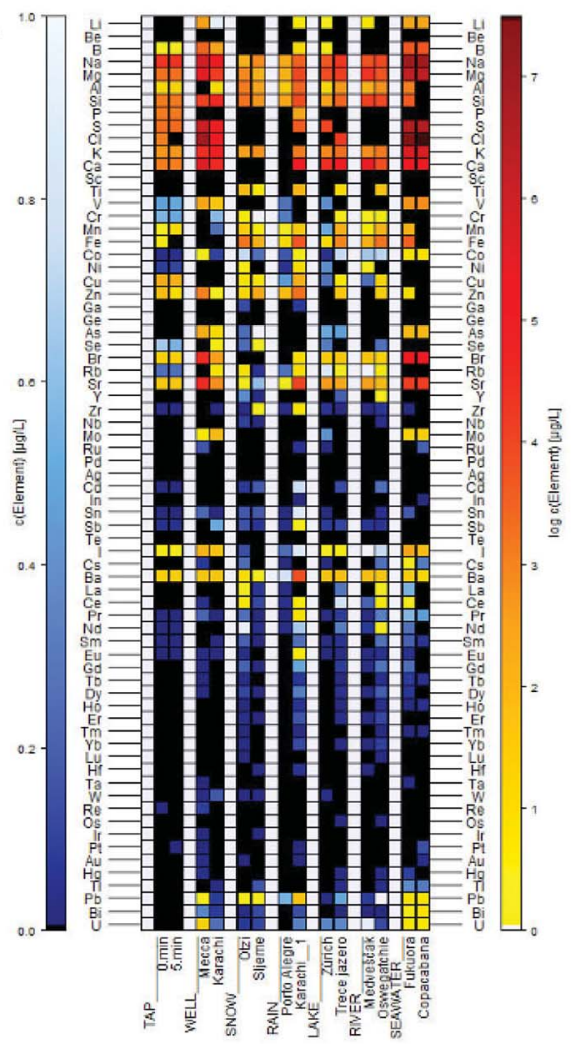

B

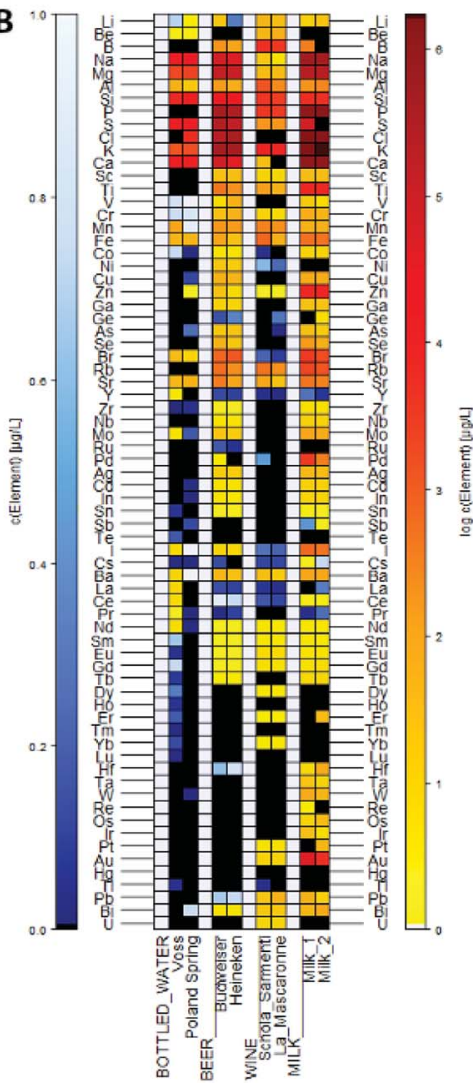

C

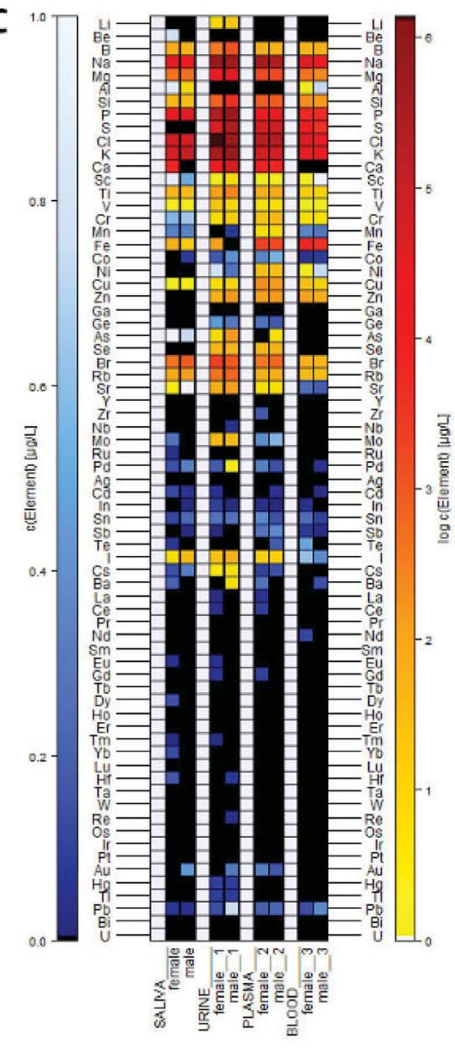

Fig. 1 (A) Element concentration patterns in (environmental) water. Trace concentrations between ND (not detected, black) and $1 \mu \mathrm{g} \mathrm{L}{ }^{-1}$ (white) are shown in shades of blue. Concentrations above $1 \mu \mathrm{g} \mathrm{L}^{-1}$ are represented by warm colours and given in a logarithmic scale and range from $>1$ $\mu \mathrm{g} \mathrm{L}^{-1}$ (light yellow) to over $3600 \mathrm{mg} \mathrm{L}^{-1}$ (dark red); (B) element concentration patterns in beverages. Trace concentrations between ND (black) and $1 \mu \mathrm{g} \mathrm{L}^{-1}$ (white) are shown in shades of blue. Concentrations above $1 \mu \mathrm{g} \mathrm{L}^{-1}$ are represented by warm colours and given in a logarithmic scale and range from $>1 \mathrm{\mu} \mathrm{L}^{-1}$ (light yellow) to over $910 \mathrm{mg} \mathrm{L}^{-1}$ (dark red); (C) element concentration patterns in biofluids. Trace concentrations between ND (black) and $1 \mu \mathrm{g} \mathrm{L}^{-1}$ (white) are shown in shades of blue. Concentrations above $1 \mu \mathrm{g} \mathrm{L}^{-1}$ are represented by warm colours and given in a logarithmic scale and range from $>1 \mathrm{~g} \mathrm{~L}^{-1}$ (light yellow) to over $1300 \mathrm{mg} \mathrm{L}^{-1}$ (dark red).

Mo, Sn, the rare earth elements La, Ce, Pr, and Sm, Hf and Re, compared to the Heineken beer (36 elements) sample. In contrast, Heineken exhibits much higher concentrations of $\mathrm{Cl}$, $\mathrm{K}, \mathrm{Cr}$, Se, and W. Sulfur concentrations should be considered lower than the actual concentration levels, as the control was $36.8 \%$ of the anticipated concentration. Other controls that were outside the $\pm 20 \%$ margin were $\mathrm{Cl}, \mathrm{Au}, \mathrm{Sc}, \mathrm{Ti}$, and $\mathrm{As}$.

Wine (Old Soul and Montana). The 'Old Soul' from California contains eleven more elements (e.g. $\mathrm{Cl}, \mathrm{Ti}, \mathrm{Mo}, \mathrm{Hg}$ and $\mathrm{U}$ ) at, in general, much higher concentrations (especially in $\mathrm{Mg}, \mathrm{Al}, \mathrm{P}, \mathrm{Ca}, \mathrm{V}$, $\mathrm{Cr}, \mathrm{Mn}, \mathrm{Fe}, \mathrm{Ni}, \mathrm{Zn}, \mathrm{Se}, \mathrm{Rb}$, and $\mathrm{Sr}$ ), in comparison to the Montana wine from Spain. Lead and copper are more highly concentrated in the Montana (Spain). Both wines are otherwise similar in composition. As in the beer samples, seven elements measured by the certified reference materials were outside the $\pm 20 \%$ range.

Milk (Farmland Fresh Dairies and Elmhurst Dairy). Besides high concentrations of $\mathrm{Na}, \mathrm{Mg}, \mathrm{Ca}, \mathrm{K}$ and $\mathrm{P}$, both milk samples show very high concentrations of $\mathrm{Au}, \mathrm{Ti}, \mathrm{Pd}$, and $\mathrm{Zn}$. Rare earth elements such as Hf, Ta, W, Re, Os, Ir, Pt (Farmland Fresh Dairies), and $\mathrm{Pb}$ are all present in concentrations above $1 \mu \mathrm{g}$ $\mathrm{L}^{-1}$. Although similar in elemental patterns, both milk samples are clearly distinguishable based on elemental concentrations.
Aluminium concentrations in both milk samples are reported to be above $400 \mathrm{mg} \mathrm{L}^{-1}$, these values should be interpreted with caution, as the control resulted in values $41 \%$ above the correct concentration.

\section{Biofluid biological samples}

Fig. 1C, ESI Tables S6.1 and 6.2.†

Saliva. Rare earth elements are present in the female, but not the male. Elements such as $\mathrm{Ti}, \mathrm{Fe}$, and $\mathrm{Cd}$ are higher in the female sample, whereas $\mathrm{Al}, \mathrm{Br}$, $\mathrm{Pd}$, and I are more highly concentrated in the male's saliva. Both samples show trace concentration of As, $\mathrm{Sn}, \mathrm{Pd}, \mathrm{Cd}$, and $\mathrm{Pb}$. Thirty-nine elements are present in the female and 31 in the male sample.

Urine. Urine samples have similar numbers of elements (female, 41; male, 40). Overall the male urine sample shows higher concentrations in most elements (e.g. As and $\mathrm{Pb}$ ). In contrast, $\mathrm{V}, \mathrm{Fe}$, and $\mathrm{Br}$ are more highly concentrated in the female sample. Lithium concentrations, however, might be higher, as control concentration is $76.3 \%$.

Blood plasma. Elemental concentrations are rather similar between the two subjects (female: 38 , and male: 36 elements), yet $\mathrm{B}, \mathrm{Fe}$, and $\mathrm{Cu}$ are higher in the female sample, whereas $\mathrm{Ti}$, 
$\mathrm{Cr}, \mathrm{Mn}$, and $\mathrm{Br}$ are higher in the male. The male plasma contains traces of As and Cd, and both samples contain Pd, Sn, $\mathrm{Au}$, and $\mathrm{Pb}$. Whole blood: both whole blood samples contain 29 elements. Overall the female sample shows higher elemental concentrations, compared to the male sample, yet the male sample contains more $\mathrm{Pb}$.

Blood samples in comparison. Overall the male sample has higher elemental concentration in the plasma sample, whereas the female shows higher concentrations in the whole blood sample. In both sexes, $\mathrm{Al}$ is present in whole blood samples, yet not in plasma. Contrary, are $\mathrm{Ca}, \mathrm{Ge}$, As (in the male), Se, Mo, and $\mathrm{Au}$ present in plasma, but not in the whole blood samples.

Biofluid samples in comparison. Elements are more abundant in the female samples, with the exception of the whole blood sample. Elements that are not present are $\mathrm{Ga}, \mathrm{Ag}, \mathrm{Pr}, \mathrm{Sm}$, $\mathrm{Tb}$, Ho, Er, Lu, Ta, W, Os, Ir Pt, Bi, and U. Overall, concentrations of elements are slightly higher in urine and elements are least concentrated in whole blood samples.

\section{Discussion}

Results presented here illustrate the potential for using the $\mathrm{MH}$ ICP-MS calibration method to detect and quantify all elements present in an aqueous sample from ${ }^{7} \mathrm{Li}$ to ${ }^{238} \mathrm{U}$ simultaneously and in as little as 1-4 $\mathrm{mL}$ of aqueous sample.

\section{Choice of internal standards}

The EPA Method 200.8 (ref. 38) suggests to use five internal standards to cover the mass range from ${ }^{7} \mathrm{Li}$ to ${ }^{238} \mathrm{U}$, with a minimum of three. We elect to use only three elements as internal standards, ${ }^{6} \mathrm{Li},{ }^{103} \mathrm{Rh}$ and ${ }^{232} \mathrm{Th}$, since each element used as an internal standard cannot be determined in unknown samples, therefore reducing the number of measurable elements. We did not find that the reduction of internal standards affected elemental quantification, as our controls were within their $\pm 20 \%$ margin.

We also decided to deviate from the suggested elements and use a highly concentrated ${ }^{6} \mathrm{Li}$ internal standard, even though lithium is a bi-isotope element $\left({ }^{6} \mathrm{Li} 7.5 \%\right.$ and ${ }^{7} \mathrm{Li} 92.5 \%$ natural abundances) to cover the lower mass ranges. Experimental data shows that the fraction of naturally occurring lithium in environmental water on mass six is so little (even with high lithium concentrations) that it does not interfere with the $100 \mathrm{ppb}{ }^{6} \mathrm{Li}$ internal standard. Although it is not known whether Rh and Th are naturally occurring in water samples, it can be expected that their concentrations are very low, and the influence of potential sample concentrations are negligible compared to the artificially added, highly concentrated isotopes within the internal standards. Even if the samples would contain $\mathrm{Rh}$ and/or Th, the additional amounts would be measurable and could be accounted for in the process of data analysis; e.g., Rh has been widely used in body fluid analysis. ${ }^{23}$

\section{Choice of calibration standards}

The combination of calibration standards used in this study represents the minimum number of standards necessary, without risking inaccurate concentration measurements due to peculiarities of inorganic chemistry, such as (1) a conflation of too many isotopes leading to polyatomic complexes, (2) elemental stability: we found that some combinations of mixes and single element standards resulted in precipitation, and (3) interferences (such as isobaric interferences, isobaric polyatomic interferences, abundance sensitivity, physical interferences, and memory interferences). ${ }^{\mathbf{3 , 8 , 1 0 , 2 1 , 3 8 , 5 3}}$ However, the multi-element calibration standards were not adequate to account for all interferences that occur across the isotopic spectrum, and hence additional single element standards are necessary (see below).

\section{Elemental limitations}

One limitation of the MH-ICP-MS calibration method is that it prohibits detection of elements with mass to charge ratios of less than 5 and more than 243. In addition, noble gases and fluorine (F) cannot be detected by our MH-ICP-MS instrument. Carbon, nitrogen and oxygen are common contaminants in argon gas and samples, which prohibits us from analysing these elements as well. Radioactive elements such as Tc, Pm, Po, At, $\mathrm{Rn}, \mathrm{Fr}, \mathrm{Ra}, \mathrm{Ac}, \mathrm{Pa}, \mathrm{Np}, \mathrm{Pu}$, and Am are not measured, as their standards are available commercially only with special permits.

\section{Interferences}

SPECTRO MS software can account for interferences that are caused by elements that have been calibrated for, and hence we cannot account for interferences caused by $\mathrm{H}, \mathrm{C}, \mathrm{N}$ and $\mathrm{O}$, other than avoiding isotopes that are affected by those interfering elements (e.g. ${ }^{56} \mathrm{Fe}$, which is interfered by ${ }^{40} \mathrm{Ar}^{16} \mathrm{O}^{+}$). Especially in alcoholic and biofluid solutions, these elements can cause non-spectral interferences, which can be accounted for by making calibration standard matrices to imitate the sample matrix (e.g. by adding EtOH into the calibration standards). Therewith, interferences would occur at similar rates in the calibration standards as well as the samples and affects can be mathematically corrected for. In general, we also cannot control for interferences caused by elements of the internal standard: ${ }^{6} \mathrm{Li}$ together with hydrogen interferes on ${ }^{7} \mathrm{Li}$, to some degree. The amount of formed ${ }^{6} \mathrm{Li}^{1} \mathrm{H}$ is being recorded by the software in the blank and subtracted from the measured ${ }^{7} \mathrm{Li}$ cps. Other interferences caused by the internal standards were not detected.

Isobaric interferences were avoided by choosing isotopes that are not affected by those interferences (e.g. measuring ${ }^{42} \mathrm{Ca}$, ${ }^{43} \mathrm{Ca}$ and ${ }^{44} \mathrm{Ca}$, instead of its most abundant isotope ${ }^{40} \mathrm{Ca}$, on which ${ }^{40} \mathrm{Ar}$ is an isobaric interference). However, isobaric interferences still occur on fifteen isotopes: ${ }^{54} \mathrm{Fe} / \mathrm{Cr},{ }^{58} \mathrm{Ni} / \mathrm{Fe}$, ${ }^{82} \mathrm{Se} / \mathrm{Kr}, \quad{ }^{86} \mathrm{Sr} / \mathrm{Kr},{ }^{102} \mathrm{Ru} / \mathrm{Pd},{ }^{115} \mathrm{In} / \mathrm{Sn},{ }^{128} \mathrm{Te} / \mathrm{Xe},{ }^{138} \mathrm{Ba} / \mathrm{La} / \mathrm{Ce}$, ${ }^{144} \mathrm{Nd} / \mathrm{Sm},{ }^{152} \mathrm{Sm} / \mathrm{Gd},{ }^{158} \mathrm{Gd} / \mathrm{Dy},{ }^{162} \mathrm{Dy} / \mathrm{Er},{ }^{184} \mathrm{~W} / \mathrm{Os},{ }^{187} \mathrm{Re} / \mathrm{Os}$, ${ }^{192} \mathrm{Os} / \mathrm{Pt}$. As $\mathrm{Kr}$ and Xe are noble gases, and potential contaminants in the carrier gas, they would be present to the same degree in the calibration standards and samples, and not affect the measurements. Assuming a natural abundance of isotopes, the percentage of, e.g. chromium, that will occur on ${ }^{54} \mathrm{Fe}$ does not change and is accounted for by the SPECTRO MS software 
when calculating the elemental concentration of iron on mass 54. The same principal applies to all other isobaric interferences.

Polyatomic interferences are abundant and cannot be avoided, but they can be accounted for. When elements that interfere with a target isotope are calibrated in a differing calibration standard than the target isotope, the SPECTRO MS software calculates the respective interferer-factor. The factors caused by interfering isotopes are then used to adjust the calibration regression of the target isotope providing a mathematically corrected elemental concentration. To keep the number of calibration standards to a minimum we used thirty single element standards to investigate the possible impact of interferences that cannot arise from the multi-element calibration standards for each sample type. With that, we assume that the factors with which interferences influence the target isotopes do not change significantly between runs of the same sample types, given that instrument conditions do not change significantly either (e.g. in oxide molecular yields). We successfully achieved and maintain instrument stability by profound maintenance and optimization of the instrument.

The formation of doubly charged ions is minimized by our optimization procedure $\mathbf{1 0 , 1 5 , 2 1 , 4 0}^{10}$ and monitored by the formation of $\mathrm{BaO}^{+} / \mathrm{Ba}^{+}$. Nevertheless, we still detected double charged strontium ions (on ${ }^{44} \mathrm{Ca}$ ) and some rare earth element (Ce, $\mathrm{Nd}$, $\mathrm{Sm}, \mathrm{Gd}$, Dy, Er, Yb, and Lu) ions between ${ }^{71} \mathrm{Ga}$ and ${ }^{88} \mathrm{Sr}$. These interferences were accounted for by establishing interferencefactors, as described for polyatomic interferences.

\section{Analytical limitations}

For environmental water samples, bottled water, wine and beer, as well as saliva, urine and plasma, we assumed to meet the requirements of matrix similarities in calibration standards, blanks, controls and samples, as all samples have a water content of $95 \%$ or higher, especially given their dilutions. We neglected certified reference materials when analysing seawater, milk and whole blood samples, since our goal in this communication was predominantly to show the wide range of applications of the described method. When pursuing research on significant numbers of seawater, milk and whole blood analysis, we strongly recommend matching the matrices of calibration standards, blank and respective controls with

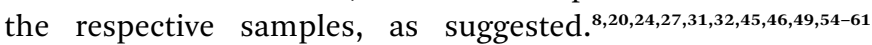
However, we did use controls for all of our sample types, but for alcoholic beverages we adjusted the control matrix to match alcohol content. Overall, the controls established were within the required $\pm 20 \%$ margin of error. Interestingly, the aluminium control is measured higher than its actual concentration (in all runs but the environmental water run) and so is sulphur in biofluids and bottled water, the control concentration, however, being at $36 \%$ only.

\section{"Simultaneous" ICP-MS}

No existing quadrupole-based se-ICP-MS is providing simultaneous detection and recording of multiple elements. There is thus some confusion in the literature regarding the use of the term "simultaneous". Many articles use this term in their titles, yet they employ a conventional quadrupole mass spectrometer

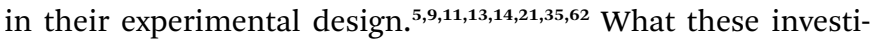
gators mean by the term simultaneous is storage and readout of multi-element data from the mass spectrometer using a multichannel analyser. Multi-element detection is still classical sequential ICP-MS, measuring one element at a time. For this reason, quantitative multi-element measurements on sequential ICP-MS instruments are somewhat constrained in the breadth of the inorganic spectrum that can be measured with any one or two multi-element calibration standards. ${ }^{2,4,6,8,10,12,15-19,22,23,31,42,45}$ The MH-ICP-MS technology and the method advanced in this study, in which six grouped standards are iteratively dispensed to calibrate the instrument, make simultaneous detection and measurement from ${ }^{7} \mathrm{Li}$ to ${ }^{238} \mathrm{U}$ possible.

\section{Samples}

In respect of the aqueous samples chosen as exemplars in this study, patterns of elemental concentrations throughout the periodic table are clearly distinguishable between the various categories of water, beverage, and biofluid. The numbers of samples are small in this communication, as in this communication we only mean to apply the method to a variety of sample types. Our future investigations will meet statistical standards and generate more robust interpretations of the results.

\section{Environmental waters}

Tap water samples. Higher concentrations of $\mathrm{Cr}, \mathrm{Fe}, \mathrm{Cu}$ and $\mathrm{Zn}$ in tap water drawn immediately in the morning, before any use, are elements associated with piping materials. ${ }^{63}$ These elements, especially $\mathrm{Fe}$ and $\mathrm{Zn},{ }^{63}$ might leach from the piping system into the water over night, when the water is not being moved. It also seems as if $\mathrm{Cl}$ decreases with the increase of water running through the tap. All elements in the tested samples monitored by the EPA are well below their maximum concentration limits. ${ }^{64}$

Well water samples. Heavy metals found in the Karachi well water are more highly concentrated compared to well water from Mecca. In contrast to previous studies, we did not find in Karachi well water heavy metals such as $\mathrm{Cr}, \mathrm{Mn}, \mathrm{Fe}, \mathrm{Ni}$, and $\mathrm{Cu},{ }^{65,66}$ but we did find $\mathrm{As}$ and $\mathrm{Hg}^{66}$ and could confirm the presence of $\mathrm{Zn}$, Cd and $\mathrm{Pb} .^{65,66}$ And unlike a previous study investigating 14 elements in ground water from Mecca, ${ }^{67}$ we found $\mathrm{Al}, \mathrm{As}, \mathrm{Ba}, \mathrm{B}, \mathrm{Zn}, \mathrm{Rb}$ and $\mathrm{V}$ to be higher and $\mathrm{Li}, \mathrm{Mn}$ and $\mathrm{Pb}$ lower concentrated, and could not detect $\mathrm{Cd}, \mathrm{Cu}, \mathrm{Fe}$ and $\mathrm{Hg}$.

Snow samples. Elements are most abundant in snow. Forty four elements ( $\mathrm{Li}, \mathrm{Al}, \mathrm{Ti}, \mathrm{V}, \mathrm{Cr}, \mathrm{Mn}, \mathrm{Fe}, \mathrm{Co}, \mathrm{Ni}, \mathrm{Cu}, \mathrm{Zn}, \mathrm{As}, \mathrm{Se}, \mathrm{Rb}$, $\mathrm{Sr}, \mathrm{Y}, \mathrm{Mo}, \mathrm{Pd}, \mathrm{Cd}, \mathrm{Sn}, \mathrm{Sb}, \mathrm{Cs}, \mathrm{Ba}, \mathrm{Pt}, \mathrm{Hg}, \mathrm{Tl}, \mathrm{Pb}, \mathrm{Bi}$, and U), ${ }^{68-70}$ including rare earth elements (La, Ce, Pr, Nd, Sm, Eu, Gd, Tb, Dy, Ho, Er, Tm, Yb, and Lu), ${ }^{70}$ are known to be transported in the atmosphere over long distances and precipitate with snow. Of these elements, Cs, Tb, and Pt are found in the Alpine snow sample only, while $\mathrm{Li}, \mathrm{V}, \mathrm{Mo}, \mathrm{Pd}$, and $\mathrm{Hg}$ were not detected in either of the snow samples investigated. Mercury is known to be 
transported from the Mediterranean ore belt to the Arctic; ${ }^{68}$ but although both sample sites are located within this pathway, none was detected. It is possible that $\mathrm{Hg}$ was in the samples but has been absorbed onto the inner walls of the HDPE tube, since these samples were not acidified with $\mathrm{HCl}$ upon collection as recommended previously. ${ }^{16}$

Rain samples. The high abundance of elements in the rain samples, and especially in rain from Karachi (47 elements) seems unexpected, as the general assumption is that rain rather holds fewer elements. As most studies investigating the chemical composition of rain focus on ions such as $\mathrm{SO}_{4}{ }^{2-}$, $\mathrm{NO}_{3}{ }^{-}$or $\mathrm{NH}_{4}{ }^{+}$(e.g. ref. 64, 71, and 72), several studies evaluate a small number of elements (e.g. Al, V, Cr, Mn, Fe, Ni, cu, Zn and Se). ${ }^{73-76}$ These elements are linked to anthropogenic pollution, dust intrusion, crustal material resuspension and marine aerosols. ${ }^{73-76}$ Without further investigation, we can only speculate where the rare earth elements in the Karachi rain originate from. Our data from Porto Alegre, where the concentration of $\mathrm{Al}, \mathrm{Fe}$ and $\mathrm{Zn}$ are particularly high $(\mathrm{Fe}>\mathrm{Al}>$ $\mathrm{Zn}$ ), is supported by. ${ }^{75}$ Elements such as $\mathrm{Al}, \mathrm{Fe}, \mathrm{Mn}, \mathrm{Ni}, \mathrm{Cu}$, and $\mathrm{Zn}$, as well as anions of $\mathrm{Cl}$ and $\mathrm{S}$ and cations of $\mathrm{Na}, \mathrm{Mg}, \mathrm{K}$, and $\mathrm{Ca}$, are related to anthropogenic sources in this region. ${ }^{75,76}$ Therefore, it can be speculated that the presence of other toxic elements such as $\mathrm{Sn}, \mathrm{Sb}, \mathrm{Pt}$, and $\mathrm{Pb}$ in our sample also originate from anthropogenic sources. The MH-ICP-MS method shows that comprehensive analyses of the elemental composition of rain water can be made routine, by evaluations that go well beyond a selection of stereotypical targeted elements, significantly contributing to the understanding of the origin, transport, precipitation/atmospheric input of elements into a geographic area of interest.

Lake samples. Lake Zurich and Treće Jezero differ significantly, as Lake Zurich is a alpine lake, while Treće Jezero is an artificially created city park lake. Treće Jezero properties might facilitate elemental accumulation and amplification, leading to the higher number and concentrations of elements compared to Lake Zurich.

River samples. The Oswegatchie carries more elements and in higher concentrations than the Medveščak feeder. The difference can be explained by the nature of the two rivers: the Medveščak is a very small mountain torrent, while the Oswegatchie is a $220 \mathrm{~km}$ long river. The sample location is at the lower course of the Oswegatchie and hence elements (such as $\mathrm{Sn}, \mathrm{Sb}$, and $\mathrm{Pb}$ ) originating from anthropogenic sources are more likely to be found there than in the mountain torrent.

Seawater samples. As expected, seawater samples have the highest concentrations of $\mathrm{Na}, \mathrm{Mg}, \mathrm{S}, \mathrm{K}$, and $\mathrm{Cl}$. In addition, $\mathrm{Br}, \mathrm{Sr}, \mathrm{Pb}, \mathrm{Bi}$, and $\mathrm{U}$ are highly abundant, when compared to other water samples from this study. The two samples differ in that elements such as $\mathrm{Al}, \mathrm{Si}, \mathrm{Mn}, \mathrm{Fe}, \mathrm{Zn}, \mathrm{Zr}, \mathrm{Sn}$, rare earth elements, $\mathrm{Ta}$, and $\mathrm{Hg}$ are present in seawater from the Copacabana only. In one study, concentration ranges of 24 elements occurring in seawater (based on reference material and general information) are given, ${ }^{8}$ yet some elements in our samples were not detected, probably due to high detection limits. Some elements, such as V, Mn, Fe, As, Co, and Pb, have much higher concentrations than stated in. ${ }^{8}$ This might be a result of differences in sample origins: our samples come from city beaches, whereas the reference values in ${ }^{8}$ derive from CRMs and generalized data. Another reason for the high concentrations of these elements might be the effect of matrix interferences in our samples that we did/could not calibrate for, which can hinder the determination of high accuracy in elemental concentrations in seawater. ${ }^{8,53}$ Matrix problems have been previously avoided by spiking seawater samples with (multi-) element standards, and using diluted seawater samples as blanks. ${ }^{55,59}$ Since our goal is to quantify every relevant element between ${ }^{7} \mathrm{Li}$ and ${ }^{238} \mathrm{U}$ in seawater, we were reluctant to use (diluted) sample material in calibration standards or blanks. In the future, we will spike the calibration standards with salt(s) to better match the seawater matrix, taking care to have less than $1000 \mathrm{ppm}$ total dissolved solids. In addition to our controls, the reference material for seawater (e.g. NASS Seawater Certified Reference Material for Trace Metals, National Research Council, Canada) $)^{\mathbf{8 , 5 9 , 6 1}}$ should be used.

\section{Beverage samples}

Concentrations among the beverages tested reveal considerable variability.

Bottled waters. Differences in elemental abundance and composition is most likely due to geological differences between the source waters. The higher chloride concentration in Poland Spring water might be a result of the common practice to chlorinate water transported from the source to the bottling plant (http://www.drinkmorewater.com); in contrast, VOSS water is bottled at the source, without prior transport. A detailed study is needed to see whether different types of bottled water (spring, artesian, municipal, purified) show differences in their patterns of elemental composition, as suggested by these two samples. A detailed study is also needed to see whether different types of bottled water (spring, artesian, municipal, purified) show differences in their patterns of elemental composition, as suggested by these two samples.

Wine samples. High concentration values for $\mathrm{S}$ in wine is likely due to sulfur dioxide added as a preservative to protect it from oxidizing and to inhibit or kill unwanted bacteria and yeast. Levels of $\mathrm{Al}$ in the wine tested are much higher than would occur in a natural fruit, and its origin is likely due to wine making infrastructure and production processes. ${ }^{57}$ Our team has sampled more than 1000 retail red and white wines from around the world, representing approximately 100 grape varieties, 250 appellations, and 900 producers from 36 countries, from which we soon expect to reveal patterns in environmental (e.g., terroir) and production processes.

Beer samples. The beer samples are distinct, especially in the amount of elements and their concentrations. This might be due to the differences in the water that is used in the brewing process, as we could show differences in environmental water, or to the beers coming from a glass (Budweiser) and can (Heineken). For example, the aluminium concentration is twice as high in the canned beer than in the bottled beer. 
Milk samples. Milk samples are distinguished from the other beverages by very high concentrations of Ti, Zn, Pd, and $\mathrm{Au}$.

\section{Biofluid samples}

Results show that some elements can only be detected in certain body fluids, e.g. rare earth elements are found in saliva and urine, but not in blood samples; Be only present in saliva and $\mathrm{Li}$ is in urine only. Investigating differences of elemental composition in different body fluids can help determine which body fluid would be best for detecting and measuring certain elements in the future. For example, elemental concentrations are reasonably high and common in saliva and urine, and hence these may be good alternatives over invasive blood sampling for having a comprehensive look at the inorganic elemental content in humans.

Whether females, in general, possess higher amounts of elements in their bodily fluids when compared to males as shown here, needs further investigation. Differences found here may be consequences of age, lifestyle (diet, medication and exercise) or permanent (geographical) residence, rather than sex.

Due to their different components, we measured blood twice: the whole blood and the plasma. We would have expected higher concentrations, or at least similarly high concentrations of elements in the whole blood sample compared to the plasma sample, as plasma is an integral part of the whole blood sample. However, we only found this to be true for Fe, which is significantly higher in the whole blood samples than in plasma, as anticipated, since it is mainly present in erythrocytes. The lack of higher/similar concentrations of elements in the whole blood sample might be due to inadequate method design: The matrices of the calibration standards, the blank, and controls were not adjusted to the respective sample matrices (plasma, whole blood), as suggested elsewhere,,$^{31,32,45}$ and hence interferences might have caused inaccurate values. ${ }^{77}$ Furthermore, sample preparation might have been insufficient: others suggested to use

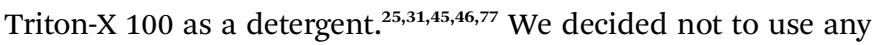
detergent to keep the samples as pure as possible, and to prevent contamination from additional chemicals. An alternative might be heated acid digestion using ultrapure $\mathrm{HNO}_{3} \cdot{ }^{32}$ Furthermore, we noticed residue on the instrument after inserting the whole blood samples, which may have been prevented if using a detergent, or a higher dilution factor. This leads us to the assumption that some parts of the sample may have not been analysed. Adjustment of the calibration standards, etc. is probably of lesser importance for the plasma samples, as plasma consists of $95 \%$ water. Here, the matrices are much more alike, compared to the whole blood sample (with $44 \%$ cellular components) and the calibration standards, etc.

Although the water content is high in body fluids (saliva: 98\%, urine: $91-96 \%$ and plasma: up to 95\%), we suggest adapting the calibration standards matrices to the respective body fluid. ${ }^{31,32,45}$ Some studies use diluted body fluids as matrix in calibration standards and blanks. ${ }^{31,45}$ However, when aiming to quantify all elements between ${ }^{7} \mathrm{Li}$ and ${ }^{238} \mathrm{U}$, in our opinion this approach is rather counterproductive. The NIST 1640 CRM has been used for blood samples, ${ }^{27}$ and we encourage the use of specific certified reference materials for blood, ${ }^{20,27,31,45,46}$ saliva, ${ }^{27,31,49}$, and urine ${ }^{24}$ in addition to the broad set of controls. Nevertheless, we have shown that it is possible to detect the entire range of elements from ${ }^{7} \mathrm{Li}$ and ${ }^{238} \mathrm{U}$ in blood samples.

\section{Applicability of a Water Fingerprinting method}

The MH-ICP-MS calibration method is essentially a "Water Fingerprinting" method, which is applicable to all aqueous samples and can be used to advance personal health in general, and public health in particular, because the monitoring of 71 elements and their patterns in water we consume and in biofluids is relatively easy, quick, and cost efficient. The method can be used to understand common concentration level ranges of each relevant inorganic element between ${ }^{7} \mathrm{Li}$ and ${ }^{238} \mathrm{U}$, as well as element patterns in drinking water, beverages, and human biofluids, exceeding by far the number of commonly monitored elements. The mapping of elemental patterns in human bodily fluids might also be beneficial for the understanding of diseases, their origin, emergences, or manner of transmission. In combination with (tap) water analysis, the method may find its application in forensics: unique total elemental patterns in environmental water might be matched to unique total elemental blood, plasma, saliva or urine patterns. The digestion of hair and tissue samples or the extension of this method to solids by a developed laser ablation-MH-ICP-MS method, will further aid the identification of specific elemental concentration patterns in human tissues.

The elemental mapping of concentration levels in bottled water and tap water will help to increase our understanding of "normal" concentration levels of all elements in water. Many elements are known to affect human health negatively, yet only 19 elements are monitored by the EPA.

Besides the method's applicability to (public) health, it may also find an application in "forensic" tracing of the origins of (bottled) water, wine, milk, beer, and other foods. Knowing the elemental composition of beverages and foods will increase our understanding of elemental distributions among consumed items (especially macro- and micronutrients) and be used to determine their origin.

Given that each water sample, may it come from rain, snow, a puddle, a river, stream, lake or the sea, has its own unique elemental concentration pattern, the Water Fingerprinting method enables global ecological stoichiometry, to map the world according to its elemental distributions and concentrations, hence revealing element flows through the environment.

\section{Conclusions}

In summary, the method facilitates the simultaneous capability of MH-ICP-MS technology for the quantification of 71 elements in aqueous solutions without the loss of elemental data by a single analytical run. The described method may be used to explore and understand the distribution of inorganic elements in aqueous solutions in the environment, those that we 
consume, and in biofluids beyond stereotypical inorganic analyses or organic analytics of carbon, nitrogen, and oxygen. With the MH-ICP-MS method it is possible to comprehensively engage the fields of ecological stoichiometry and metabolic ecology and contribute to many fields relating to states of health and the environment. Additionally, once elemental distribution and concentration patterns for specific environments have been established, the method can and should be applied to answer pending and vexing questions in fields that relate the present to the past, such as would relate to the study of the paleoenvironment and climate change.

\section{Conflicts of interest}

There are no conflicts to declare.

\section{Acknowledgements}

We thank Johannes Pfleging for obtaining the Otzi snow sample and Maham Khan for obtaining the Mecca water and Karachi rain samples. We thank Nick Michelson for help in creating the heat maps. The technical support of George Cisneros Jr and Emily $\mathrm{Xu}$ is also gratefully acknowledged, as is the method applications support of Willi Barger. Reviewer appreciation for the scope of the work is acknowledged, and critique was also greatly appreciated, which we used to significantly improve the paper. Research support was provided by the Max Planck Prize to TGB, endowed by the German Federal Ministry of Education and Research to the Max Planck Society and the Alexander von Humboldt Foundation. Further financial support came from the Human Microassay, Inc., Collierville, TN, USA to MB.

\section{References}

1 C. Ding, C. Zhu, D. Liu, M. Dong, A. Zhang, Y. Pan and H. Yan, Zhonghua Yufang Yixue Zazhi, 2012, 46, 745-749.

2 A. Gonzalvez, S. Armenta, A. Pastor and M. De La Guardia, J. Agric. Food Chem., 2008, 56, 4943-4954.

3 J. M. Henshaw, E. M. Heithmar and T. A. Hinners, Anal. Chem., 1989, 61, 335-342.

4 M. Jabłońska-Czapla, S. Szopa, K. Grygoyć, A. Łyko and R. Michalski, Talanta, 2014, 120, 475-483.

5 N. Khan, I. S. Jeong, I. M. Hwang, J. S. Kim, S. H. Choi, E. Y. Nho, J. Y. Choi, B.-M. Kwak, J.-H. Ahn and T. Yoon, Food Chem., 2013, 141, 3566-3570.

6 M. Krachler and W. Shotyk, Sci. Total Environ., 2009, 407, 1089-1096.

7 J. Kubová, V. Nevoral and V. Streško, J. Anal. At. Spectrom., 1994, 9, 241-243.

8 P. Leonhard, R. Pepelnik, A. Prange, N. Yamada and T. Yamada, J. Anal. At. Spectrom., 2002, 17, 189-196.

9 G. R. Loope, L. R. Kump and M. A. Arthur, Chem. Geol., 2013, 351, 195-208.

10 D. Pröfrock and A. Prange, Appl. Spectrosc., 2012, 66, 843868.

11 R. Rahil-Khazen, H. Henriksen, B. Bolann and R. Ulvik, Scand. J. Clin. Lab. Invest., 2000, 60, 677-686.
12 V. S. Šelih, M. Šala and V. Drgan, Food Chem., 2014, 153, 414423.

13 V. F. Taylor, H. P. Longerich and J. D. Greenough, J. Agric. Food Chem., 2003, 51, 856-860.

14 D. Yeghicheyan, C. Bossy, M. Bouhnik Le Coz, C. Douchet, G. Granier, A. Heimburger, F. Lacan, A. Lanzanova, T. C. Rousseau and J. L. Seidel, Geostand. Geoanal. Res., 2013, 37, 449-467.

15 J. De Boer, W. Verweij, T. Van Der Velde-Koerts and W. Mennes, Water Res., 1996, 30, 190-198.

16 H. Louie, C. Wong, Y. J. Huang and S. Fredrickson, Anal. Methods, 2012, 4, 522-529.

17 K. J. Stetzenbach, M. Amano, D. K. Kreamer and V. F. Hodge, Groundwater, 1994, 32, 976-985.

18 N. Khan, I. S. Jeong, I. M. Hwang, J. S. Kim, S. H. Choi, E. Y. Nho, J. Y. Choi, K. S. Park and K. S. Kim, Food Chem., 2014, 147, 220-224.

19 N. Mohd-Taufek, D. Cartwright, M. Davies, A. K. Hewavitharana, P. Koorts, P. N. Shaw, R. Sumner, E. Lee and K. Whitfield, Food Anal. Methods, 2016, 9, 20682075.

20 F. Barbosa, M. H. C. Rodrigues, M. R. Buzalaf, F. J. Krug, R. F. Gerlach and J. E. Tanus-Santos, Arch. Toxicol., 2006, 80, 633-637.

21 S. D'Ilio, N. Violante, M. Di Gregorio, O. Senofonte and F. Petrucci, Anal. Chim. Acta, 2006, 579, 202-208.

22 R. Forrer, K. Gautschi and H. Lutz, Biol. Trace Elem. Res., 2001, 80, 77.

23 J.-P. Goullé, L. Mahieu, J. Castermant, N. Neveu, L. Bonneau, G. Lainé, D. Bouige and C. Lacroix, Forensic Sci. Int., 2005, 153, 39-44.

24 P. Heitland and H. D. Köster, Clin. Chim. Acta, 2006, 365, 310-318.

25 D. Koh, V. Ng, L. Chua, Y. Yang, H. Ong and S. Chia, Occup. Environ. Med., 2003, 60, 696-698.

26 T. D. Lyon, G. S. Fell, R. C. Hutton and A. N. Eaton, J. Anal. At. Spectrom., 1988, 3, 265-271.

27 J. Nriagu, B. Burt, A. Linder, A. Ismail and W. Sohn, Int. J. Hyg. Environ. Health, 2006, 209, 109-121.

28 I. Rodushkin and F. Ödman, J. Trace Elem. Med. Biol., 2001, 14, 241-247.

29 I. Rodushkin, F. Ödman and S. Branth, Fresenius J. Anal. Chem., 1999, 364, 338-346.

30 I. Rodushkin, F. Ödman, R. Olofsson and M. D. Axelsson, J. Anal. At. Spectrom., 2000, 15, 937-944.

31 J. F. Staff, A.-H. Harding, J. Morton, K. Jones, E. A. Guice and T. McCormick, Toxicol. Lett., 2014, 231, 270-276.

32 M. Vaughan, A. Baines and D. Templeton, Clin. Chem., 1991, 37, 210-215.

33 D. Wang, X. Du and W. Zheng, Toxicol. Lett., 2008, 176, 4047.

34 S. Zhang, X. Zhuo and D. Ma, Fayixue Zazhi, 2012, 28, 456460, 463.

35 F. C. Bressy, G. B. Brito, I. S. Barbosa, L. S. Teixeira and M. G. A. Korn, Microchem. J., 2013, 109, 145-149.

36 C. D. Garbe-Schönberg, Geostand. Geoanal. Res., 1993, 17, 81-97. 
37 C. J. Kantipuly and A. D. Westland, Talanta, 1988, 35, 1-13. 38 S. Long and T. Martin, Determination of trace elements in waters and wastes by inductively coupled plasma-mass spectrometry: Method 200. 8. Version 4. 0, Environmental Protection Agency, Environmental Monitoring Systems Lab, Cincinnati, OH (USA), 1989.

39 WHO, Guidelines for drinking-water quality, Report 978-92-4154815-1, 4th edn, 2011.

40 D. Ardelt, A. Polatajko, O. Primm and M. Reijnen, Anal. Bioanal.Chem., 2013, 405, 2987-2994.

41 G. D. Schilling, F. J. Andrade, J. H. Barnes, R. P. Sperline, M. B. Denton, C. J. Barinaga, D. W. Koppenaal and G. M. Hieftje, Anal. Chem., 2006, 78, 4319-4325.

42 J. Fernandez-Turiel, J. Llorens, F. López-Vera, C. GómezArtola, I. Morell and D. Gimeno, Fresenius J. Anal. Chem., 2000, 368, 601-606.

43 EPA, Drinking Water Standards and Health Advisories, Report EPA 822-S-12-001, U.S. Environmental Protection Agency, Washington, DC, 2012.

$44 \mathrm{EU}$, Council Directive 98/83/EC on the quality of water intented for human consumption, Official Journal of the European Communities, Brussels, Belgium, 1998.

45 P. Heitland and H. D. Köster, J. Trace Elem. Med. Biol., 2006, 20, 253-262.

46 A. Schütz, I. A. Bergdahl, A. Ekholm and S. Skerfving, Occup. Environ. Med., 1996, 53, 736-740.

47 C. Feldman, Anal. Chem., 1974, 46, 99-102.

48 Y. J. Kim, Y. K. Kim and H. S. Kho, Oral Dis., 2010, 16, 823830.

49 Z. T. Dame, F. Aziat, R. Mandal, R. Krishnamurthy, S. Bouatra, S. Borzouie, A. C. Guo, T. Sajed, L. Deng, H. Lin, P. Liu, E. Dong and D. S. Wishart, Metabolomics, 2015, 11, 1864-1883.

50 D. Wang, Y. Shimoda, S. Wang, Z. Wang, J. Liu, X. Liu, H. Jin, F. Gao, J. Tong and K. Yamanaka, Environ. Health Preventative Med., 2017, 22, 45.

51 J. Morton, E. Leese, A.-H. Harding, K. Jones and O. Sepai, Biomonitoring, 2014, 1, 75-84.

52 OVAN, http://www.ovan.de, 2016.

53 R. Thomas, Practical guide to ICP-MS: a tutorial for beginners, CRC Press, 2013.

54 A. Ataro, R. I. McCrindle, B. M. Botha, C. M. E. McCrindle and P. P. Ndibewu, Food Chem., 2008, 111, 243-248.

55 M. P. Field, J. T. Cullen and R. M. Sherrell, J. Anal. At. Spectrom., 1999, 14, 1425-1431.

56 N. Herwig, K. Stephan, U. Panne, W. Pritzkow and J. Vogl, Food Chem., 2011, 124, 1223-1230.
57 F. F. Lopez, C. Cabrera, M. L. Lorenzo and M. C. Lopez, Sci. Total Environ., 1998, 220, 1-9.

58 F. A. R. Martino, M. a. L. F. Sánchez and A. Sanz-Medel, Anal. Chim. Acta, 2001, 442, 191-200.

59 A. Milne, W. Landing, M. Bizimis and P. Morton, Anal. Chim. Acta, 2010, 665, 200-207.

60 H. J. Reid, A. A. Bashammakh, P. S. Goodall, M. R. Landon, C. O'Connor and B. L. Sharp, Talanta, 2008, 75, 189-197.

61 T. Sumida, T. Nakazato and H. Tao, Bunseki Kagaku, 2003, 52, 619-626.

62 H. Peng, N. Zhang, M. He, B. Chen and B. Hu, Talanta, 2015, 131, 266-272.

63 M. Li, Z. Liu, Y. Chen and Y. Hai, Water Res., 2016, 106, 593603.

64 V. V. Bhaskar and P. Rao, J. Atmos. Chem., 2017, 74, 23-53.

65 M. A. Arain, Z. Haque, N. Badar and N. Mughal, JPMA, J. Pak. Med. Assoc., 2009, 59, 270-274.

66 M. A. Jaleel, R. Noreen and A. Baseer, J. Ayub. Med. Coll. Abbottabad, 2001, 13, 12-15.

67 M. A. M. Sharaf and A. M. Subyani, International Journal of Scientific and Engineering Research, 2011, 2, 1-14.

68 AMAP, Arctic Pollution 2002: Persistent Organic Pollutants, Heavy Metals, Radioactivity, Human Health, Changing Pathways, 2002.

69 E. Steinnes, T. Berg and H. T. Uggerud, Sci. Total Environ., 2011, 412, 351-358.

70 L. Yuefang, L. Zhen, G. Cozzi, C. Turetta, C. Barbante, H. Ju and X. Longfei, Chemosphere, 2018, DOI: 10.1016/ j.chemosphere.2018.01.039.

71 K. Budhavant, P. Rao, P. Safai, L. Granat and H. Rodhe, Atmos. Environ., 2014, 88, 59-65.

72 S. Tyagi, S. Tiwari, A. Mishra, A. Chatterjee and D. S. Bisht, Earth Science India, 2016, 9, 150-166.

73 I. Anil, O. Alagha and F. Karaca, Air Qual. Atmos. Health, 2017, 10, 1193-1206.

74 B. M. Ghauri, M. I. Mirza, R. Richter, V. A. Dutkiewicz, A. Rusheed, A. R. Khan and L. Husain, Chemosphere: Global Change Sci., 2001, 3, 51-63.

75 D. Migliavacca, E. Teixeira, M. Pires and J. Fachel, Atmos. Environ., 2004, 38, 1641-1656.

76 D. Migliavacca, E. Teixeira, F. Wiegand, A. Machado and J. Sanchez, Atmos. Environ., 2005, 39, 1829-1844.

77 R. Chemnitzer, Analytik News, Direkte Bestimmung von Spurenelementen in Körperflüssigkeiten mittels ICPMassenspektrometrie, Dr. Beyer Internet-Beratung, 2015. 